13.3

\title{
Электрохимический контроль электронной проводимости тонких пленок металлоорганических полимеров
}

\author{
(ㄱ) М.П. Карушев, А.М. Тимонов \\ Физико-технический институт им. А.Ф. Иофрфе РАН, Санкт-Петербург, Россия \\ E-mail: mkarushev@mail.ioffe.ru
}

Поступило в Редакцию 16 апреля 2021г.

В окончательной редакции 11 мая 2021 г.

Принято к публикации 11 мая 2021 г.

\begin{abstract}
Методом электрохимической in situ проводимости исследована зависимость проводимости тонких пленок полимерных комплексов никеля с $\mathrm{N}_{4}$-лигандами макроциклического и хелатного строения от уровня легирования. Установлено, что электрохимическое окно проводимости полимеров зависит от структуры мономеров и достигает $1.2 \mathrm{~V}$ для макроциклического комплекса. Электрохимическое легирование позволяет изменять сопротивление исследованных материалов на четыре порядка величины.
\end{abstract}

Ключевые слова: электропроводящие полимеры, $\mathrm{N}_{4}$-лиганды, полимерные комплексы никеля, метод электрохимической in situ проводимости.

DOI: 10.21883/PJTF.2021.16.51329.18830

Электропроводность органических или металлоорганических сопряженных полимерных ионно-электронных проводников может регулироваться как химической природой (структурой) полимера, так и электрохимическим окислительно-восстановительным потенциалом [1]. Это уникальное свойство делает возможным их применение в электрохимических устройствах, в том числе в биосенсорах [2], накопителях энергии [3], транзисторах [4]. В настоящей работе был получен новый электропроводящий полимер поли-[7,8,15,16,17,18-гексагидробензол $[e, m][1,4,8,11]$ тетраазоциклотетрадецинато(2-)]никель(II) (поли-[NiCyen]), впервые исследована зависимость электронной проводимости сопряженных никелевых металлополимеров с основаниями Шиффа, содержащими четыре донорных атома азота $\left(\mathrm{N}_{4}\right)$, от электрохимически индуцированного уровня легирования для оценки перспективности их как материалов электрохимических транзисторов.

Проводящие полимеры синтезированы из исходных комплексов никеля (II), графические формулы, обозначения и структуры которых показаны на рис. 1. Методики синтеза исходных соединений и результаты рентгеноструктурного анализа приведены в [5,6]. Получение полимерных пленок poly-[NiAmben] и poly-[NiCyen] осуществлялось методом электроокислительной полимеризации из растворов комплексов на поверхности платинового гребенчатого электрода (Interdigitated array electrode, MicruX Technologies), схема которого приведена на рис. 2, $a$. Электрод представляет собой две „гребенки“, вложенные одна в другую, так что зазоры между „зубьями“ составляют $5 \mu \mathrm{m}$. Обе „гребенки“ подключаются к выходам бипотенциостата VSP (BioLogic Science Instruments). Электрод помещается в электрохимическую ячейку, заполненную раствором $\left(10^{-3} \mathrm{~mol} \cdot \mathrm{1}^{-1}\right)$ исходного комплекса в 1,2-дихлорэтане
(ДХЭ)(Aldrich), содержащим также $\left.0.05 \mathrm{~mol} \cdot 1^{-1}\right)$ фонового электролита $\left[\left(\mathrm{C}_{2} \mathrm{H}_{5}\right)_{4} \mathrm{~N}\right] \mathrm{BF}_{4}$ (Aldrich). Вспомогательный электрод - стеклоуглеродная пластина, электрод сравнения - неводный $\mathrm{Ag} / \mathrm{Ag}^{+}$(MW-1085, BASi), имеющий потенциал $-0.3 \mathrm{~V}$ относительно электрода сравнения $\mathrm{Ag} / \mathrm{AgCl} /$ насыщенный раствор $\mathrm{NaCl}$; все потенциалы приведены по отношению к неводному электроду сравнения $\mathrm{Ag} / \mathrm{Ag}^{+}$. Ячейка помещалась в заполненный аргоном перчаточный бокс с концентрацией паров воды и кислорода $<1$ ppm.

Нанесение полимерных пленок осуществлялось посредством электроокислительной полимеризации в режиме циклической вольтамперометрии в диапазоне потенциалов от -0.9 до $1.3 \mathrm{~V}$ при скорости сканирования потенциала $10 \mathrm{mV} / \mathrm{s}$. Механизм полимеризации poly[NiAmben] подробно рассмотрен в работе [7]. Между „гребенками“ электрода поддерживалась разность потенциалов $5 \mathrm{mV}$. Такой режим позволяет одновременно наблюдать за увеличением количества полимера на „гребенках“(увеличение вольтамперометрического отклика от цикла к циклу, рис. 2, b), а также за возникновением (при заполнении полимером зазора между отдельными „зубьями“) и увеличением проводимости при росте толщины полимера [8]. Синтез останавливали, когда увеличение количества полимера на электроде переставало отражаться на проводимости (токе утечки) между электродами. После синтеза электроды промывались ДХЭ, высушивались и переносились в раствор фонового электролита, где регистрировались вольтамперограммы электродов и значения токов утечки между „гребенками“ при изменении разности потенциалов между гребенками от 0 до $20 \mathrm{mV}$. При этом наблюдалась линейная зависимость тока утечки от приложенной разности потенциалов. 

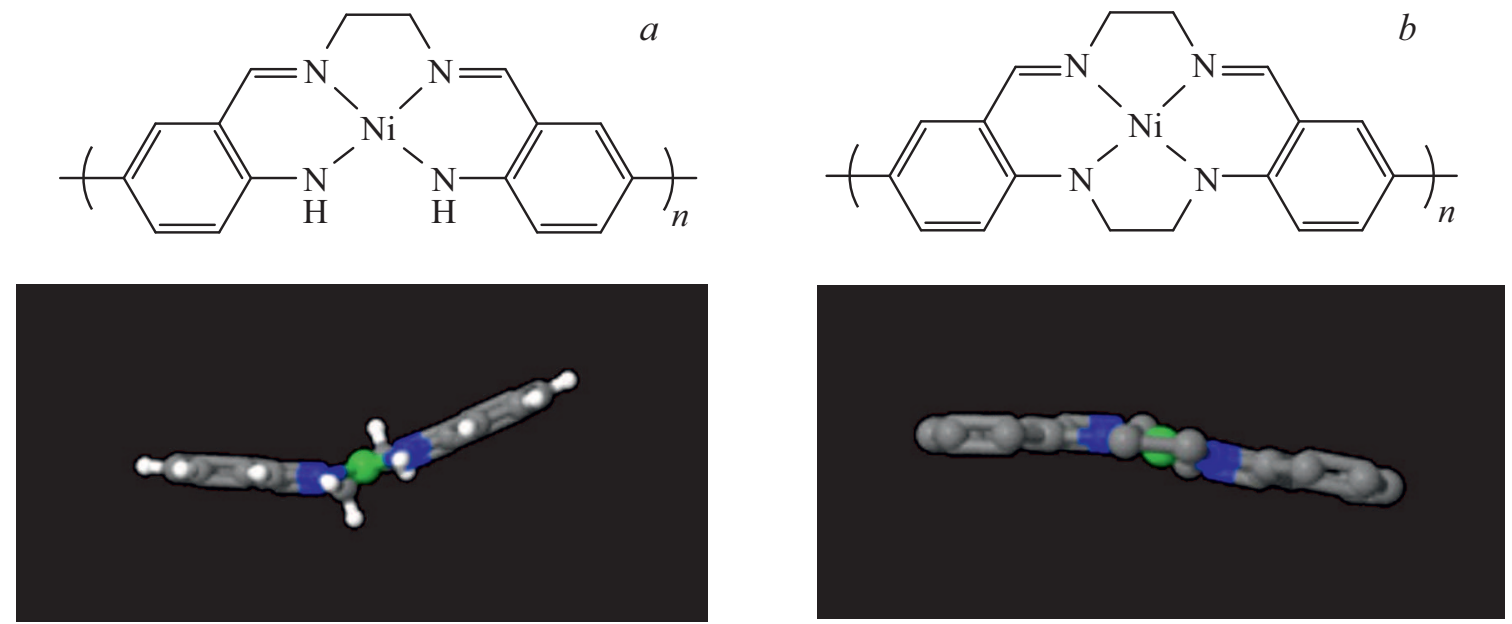

Рис. 1. Графические формулы полимеров и проекции структур в плоскости одного из фенильных колец исходных комплексов никеля (II), использованных для получения полимеров poly-[NiAmben] $(a)$ и poly-[NiCyen] $(b)$.

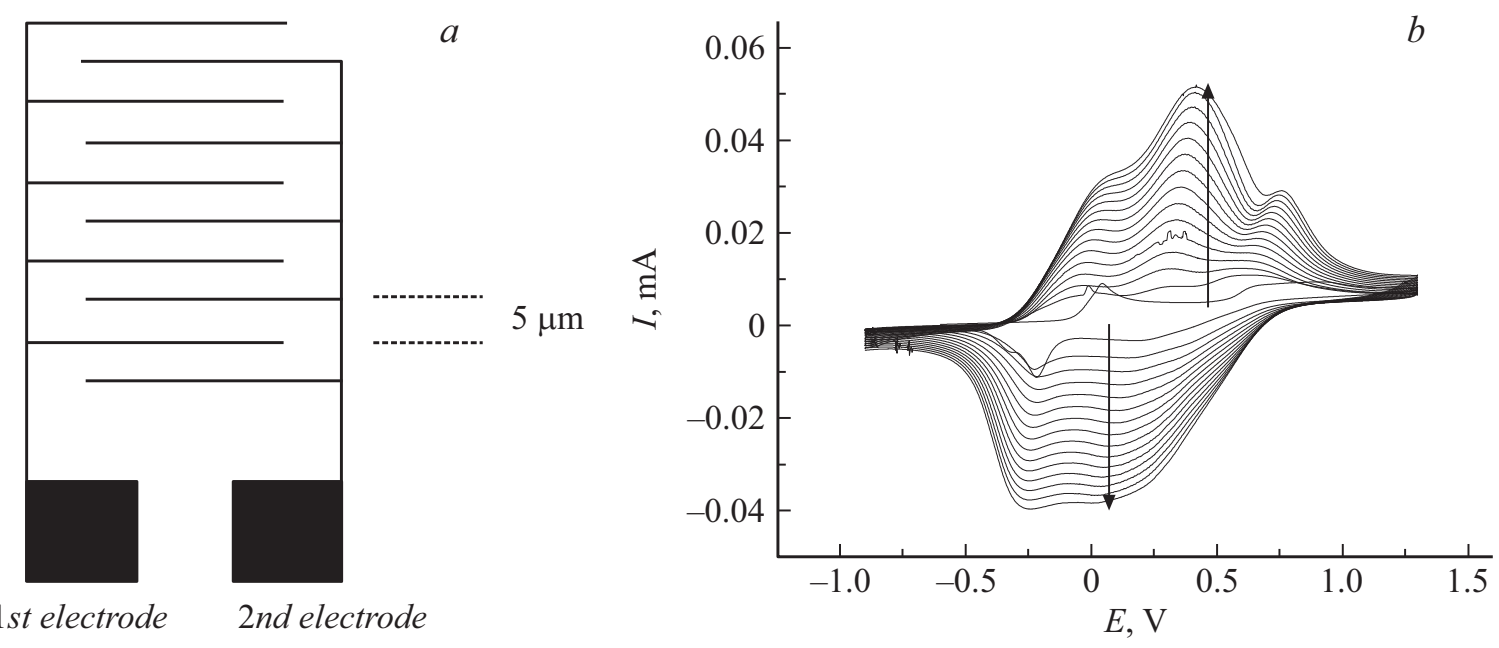

Рис. 2. Схема гребенчатого электрода $(a)$ и циклические вольтамперограммы полимеризации комплекса $[\mathrm{NiCyen]}(b)$. Cтрелками обозначены направления роста токов анодных и катодных волн. Остальные пояснения приведены в тексте.

Теория переноса заряда в проводящих полимерах, в которых происходят окислительно-восстановительные (редокс) процессы, предполагает наличие в составе каждого повторяющегося фрагмента полимера редоксцентров - атомов или групп, участвующих в редоксреакциях [9]. В слабокоординирующихся растворителях, к которым относится ДХЭ, редокс-центры в полимерных комплексах никеля с основаниями Шиффа локализованы на органических лигандах [10]. Когда редоксцентры имеют разное зарядовое состояние, между ними возможен обмен электроном через разветвленную систему $\pi$-связей лигандов. Проводимость максимальна при одинаковых концентрациях окисленных и восстановленных редокс-центров. Таким образом, проводимость $\propto k[O x][R e d]$, где $k$ - так называемая константа скорости самообмена электроном между редокс-центрами, зависящая от их химической природы [9], а $[O x]$ и $[R e d]$ - концентрации окисленной и восстановленной форм редокс-центров. Когда полимер полностью окислен или полностью восстановлен, т. е. все его редокс-центры находятся в одном зарядовом состоянии, перенос заряда в полимере невозможен и его проводимость близка к нулю.

В соответствии с приведенными теоретическими положениями проводимость исследуемых полимеров в полностью восстановленном состоянии (при потенциале менее $-0.32 \mathrm{~V}$ для poly-[NiAmben] и $-0.40 \mathrm{~V}$ для poly[NiCyen]), а также в полностью окисленном состоянии (при потенциале более 0.60 и $0.80 \mathrm{~V}$ соответственно) стремится к нулю (рис. 3). При начале процесса окисления в полимере проводимость резко возрастает, достигая максимальных значений в области максимумов тока вольтамперограмм, после чего падает вслед за падением тока вольтамперограмм. Ширина области потенциалов, в которой возможно управление проводимостью поли- 

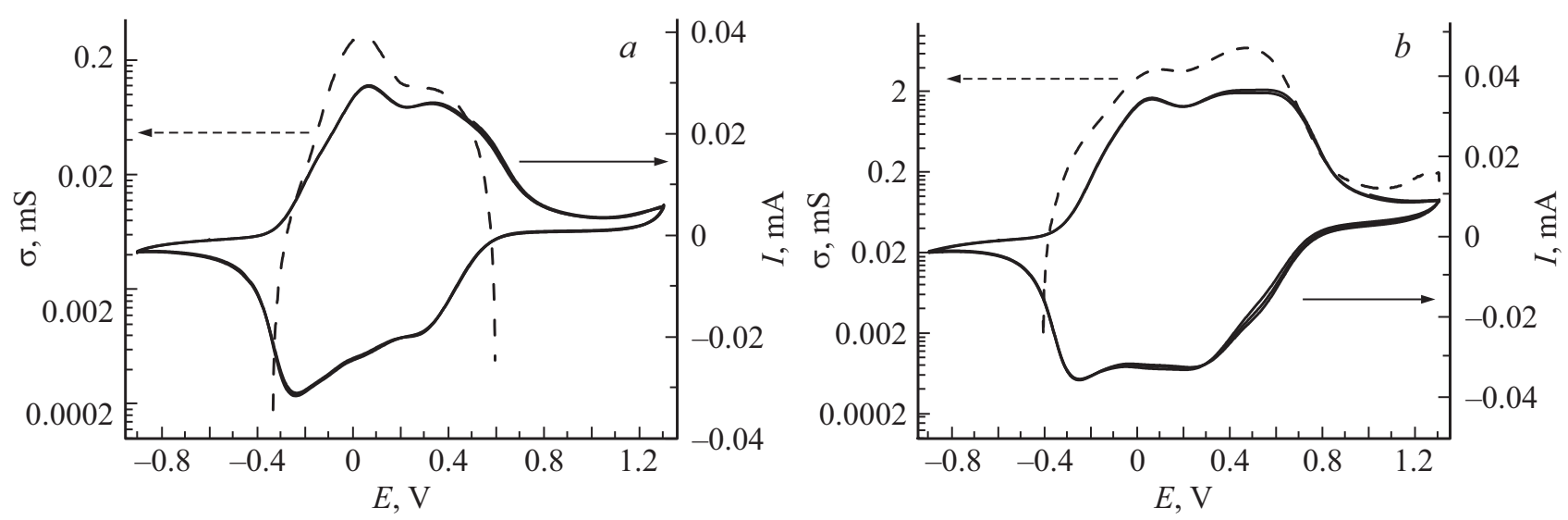

Рис. 3. Вольтамперограммы полимерных пленок poly-[NiAmben] (a) и poly-[NiCyen] (b), зарегистрированные на гребенчатом электроде в фоновом растворе при скорости сканирования потенциала $10 \mathrm{mV} / \mathrm{s}$ (сплошные линии). Штриховые линии зависимости in situ проводимости пленок от потенциала в диапазонах от -0.32 до $0.60 \mathrm{~V}(a)$ и от -0.40 до $1.25 \mathrm{~V}(b)$.

мера, составляет $1 \mathrm{~V}$ для poly-[NiAmben] и $1.2 \mathrm{~V}$ для poly-[NiCyen].

На вольтамперограммах (рис. 3) наблюдается два максимума анодного тока, что свидетельствует о протекании двух процессов окисления полимера с участием двух типов редокс-центров. В соответствии с этим на зависимостях проводимости от потенциала также присутствуют два максимума в тех же областях, что и максимумы на вольтамперограммах.

Максимальная проводимость poly-[NiCyen] (рис. 3,b) более чем в 20 раз превышает максимальную проводимость poly-[NiAmben] (рис. 3,a), что можно объяснить различиями в структуре полимеров. На микроуровне перенос электрона в проводящих полимерах осуществляется двумя путями: вдоль цепи полимера за счет системы сопряженных связей между фрагментами одной цепи (внутрицепочечный) и между цепями полимера за счет межмолекулярных взаимодействий между фрагментами разных цепей (межцепочечный). Очевидно, что из-за неплоскостной структуры комплекса [NiAmben] (рис. $1, a)$ второй путь транспорта заряда в этом полимере серьезно затруднен.

Как следует из данных рис. 3, проводимость poly-[NiCyen] изменяется при электрохимическом легировании примерно на четыре порядка, а проводимость poly-[NiAmben] — на три порядка.

Таким образом, в работе впервые синтезирован электропроводящий полимер poly-[NiCyen] и показана возможность управления его проводимостью методом электрохимического легирования в пределах четырех порядков величины, что соответствует лучшим достижениям в этой области, имеющимся в настоящее время [1].

\section{Конфликт интересов}

Авторы заявляют, что у них нет конфликта интересов.

\section{Список литературы}

[1] S.T.M. Tan, A. Giovannitti, A. Melianas, M. Moser, B.L. Cotts, D. Singh, I. McCulloch, A. Salleo, Adv. Funct. Mater., 31 (19), 2010868 (2021). DOI: 10.1002/adfm.202010868

[2] G. Méhes, A. Roy, X. Strakosas, M. Berggren, E. Stavrinidou, D.T. Simon, Adv. Sci., 7 (15), 2000641 (2020). DOI: $10.1002 /$ advs.202000641

[3] Е.В. Белецкий, Ю.А. Волосатова, С.Н. Елисеева, О.В. Левин, Электрохимия, 55 (4), 500 (2019).

DOI: $10.1134 / \mathrm{S} 0424857019030034$

[Пер. версия: 10.1134/S1023193519030030].

[4] J. Rivnay, S. Inal, A. Salleo, R.M. Owens, M. Berggren, G.G. Malliaras, Nature Rev. Mater., 3, 17086 (2018). DOI: 10.1038/natrevmats.2017.86

[5] G. Brewer, J. Jasinski, W. Mahany, L. May, S. Prytkov, Inorg. Chim. Acta, 232 (1-2), 183 (1995). DOI: $10.1016 / 0020-1693(94) 04387-b$

[6] E.N. Maslen, L.M. Engelhardt, A.H. White, J. Chem. Soc., Dalton Trans., N 16, 1799 (1974). DOI: $10.1039 / \mathrm{dt} 9740001799$

[7] M. Karushev, E. Smirnova, I. Chepurnaya, Molecules, 26 (9), 2646 (2021). DOI: 10.3390/molecules26092646

[8] G. Salinas, B.A. Frontana-Uribe, ChemElectroChem, 6 (16), 4105 (2018). DOI: 10.1002/celc.201801488

[9] А.М. Тимонов, С.В. Васильева, Сорос. образоват. журн., 6 (3), 33 (2000).

[10] E. Dmitrieva, M. Rosenkranz, J.S. Danilova, E.A. Smirnova, M.P. Karushev, I.A. Chepournaya, A.M. Timonov, Electrochim. Acta, 283, 1742 (2018). DOI: $10.1016 /$ j.electacta.2018.07.131

\section{Финансирование работы}

Работа выполнена при поддержке Российского научного фонда (грант № 19-73-00246). 